\title{
Retinoblastoma occurring in four successive generations
}

\author{
CLIVE MIGDAL* \\ From the Department of Ophthalmology, St Bartholomew's Hospital, London
}

The hereditary aspect of retinoblastoma, the most common intraocular tumour in childhood, has been well established (François and van Leuven, 1964; Vogel, 1967; Sorsby, 1972; Warburg, 1974).

These tumours have been reported in up to three successive generations (Morgan and Bair, 1968), but there is no proven evidence of retinoblastoma occurring in four successive generations.

This report deals with a family in which retinoblastoma has been found in four generations, and it also emphasizes that an apparently unaffected individual can still transmit the affected gene to his offspring, who may, in turn, manifest the disease.

\section{Case reports}

CASE I

(I/8, male, born $189 \mathrm{I}$, the youngest of a large family, having five older brothers and two older sisters)

Tumours were discovered in the right eye at the age of 3 years, and in the left at the age of $4 \frac{1}{2}$ years. Both eyes were subsequently enucleated at the Glasgow Royal Infirmary, and the lesions were diagnosed as 'retinal gliomata'. No further treatment was necessary, and the patient is still alive and well and living in Scotland. Detailed inquiries revealed no history of similar disease among the grandparents, parents, siblings, or any other relatives.

CASE 2

(II/I, male, born $192 \mathrm{I}$, the eldest son of Case $\mathrm{I})$

At the age of 3 years, the left eye was noted to have 'changed colour', taking on a 'blank' appearance. Examination revealed a white tumour projecting into the vitreous and the eye was enucleated. Three years later, after the discovery of a similar lesion, the right eye was also removed. No further treatment was given, and the patient has had no local or systemic recurrence.

CASE 3

(II/2, male, born 1923, the second son of Case I)

A tumour was discovered in the left eye on routine examination at the age of 6 years. The eye was subsequently enucleated, histological investigation confirming the diagnosis of retinoblastoma. No further treatment

*Present address: Department of Ophthalmology, Groote Schuur Hospital and Observatory, Cape Town, South Africa

Address for reprints: Dr C. Migdal, Department of Ophthalmology, Groote Schuur Hospital and Observatory, Cape Town, South Africa

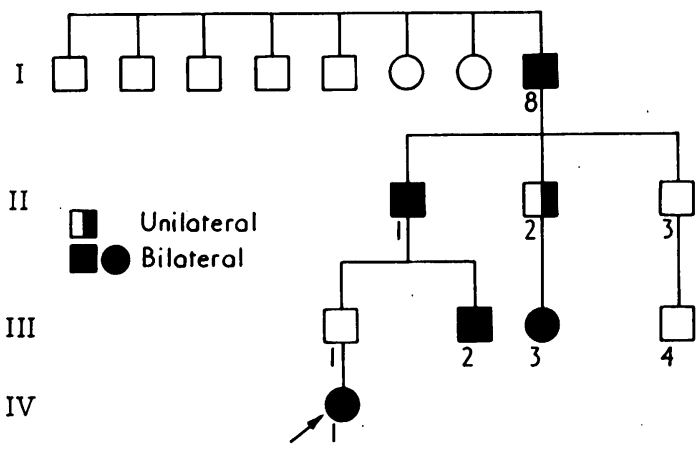

FIGURE Pedigree of family reported with retinoblastoma occurring in four successive generations

Conventional symbols are used: squares indicate males; circles females

was required. The right eye is unaffected, and the patient is still a keen and accurate pheasant shooter.

CASE 4

(III/1, male, born 1949, the elder son of Case 2)

No eye disease was evident. The fundus was normal, with no evidence of retinal changes indicating spontaneous regression of retinoblastoma; however, this man's child had bilateral retinoblastoma, see Case 7.

CASE 5

(III/2, male, born 1955, the younger son of Case 2, and the younger brother of the previous case)

At a routine check, a tumour was discovered in the left eye at the age of $3 \frac{1}{2}$ months; the eye was then enucleated. Retinoblastoma was also discovered in the right eye at the age of 9 months; this was treated with radiotherapy. Follow-up examinations revealed no recurrence of the tumour in the right eye, while the left socket remained clear. Visual acuity in the right eye was normal.

CASE 6

(III/3, female, born 1954, the only child of Case 3)

Tumours were noted in both eyes at the age of $\mathbf{I}$ year, and these were treated with radiotherapy. The tumour in the right eye responded well, but the tumour in the left, which was close to the optic nerve head, retrogressed, and the eye had to be enucleated. Histological examination confirmed the presence of retino- 
blastoma. A sequel to treatment has been the development of a minimal postirradiation cataract in the right eye.

\section{CASE 7}

(IV/I, female, born 1973, the only child of Case 4, himself not affected with retinoblastoma)

Routine examination under general anaesthesia at the age of 1 year revealed the presence of bilateral retinoblastoma. The tumour in the right eye was $3 \mathrm{~mm}$ in diameter, and situated just above the macula. The small tumour in the left eye was near the optic disc. The child was otherwise well. Both tumours were treated with the Xenon arc laser. At follow-up examinations during the course of 5 months until the time of writing, the tumours appeared inert, with no evidence of new primary tumours. The child will continue to be examined at regular intervals.

\section{Discussion}

This family with retinoblastoma is of interest because the tumour has occurred in four successive generations.

Two forms of retinoblastoma are encountered, namely sporadic and familial. A brief résumé of the disease pattern of these tumours follows:

\section{Sporadic cases}

These are cases in which there is no family history of the disease.

Sporadic cases may, in turn, be divided into somatic and germinal mutants.

\section{Somatic mutants}

As the genetic abnormality is in the retina itself, the disease is not transmitted to the offspring. Only one eye is affected.

\section{Germinal mutants}

The genetic abnormality lies in the germinal epithelial cells of the gonads of one parent (who is clinically normal), with the result that the mutation is passed on to the next generation by the gametes. The disease is usually bilateral.

Knudson (197r) has put forward the hypothesis that retinoblastoma is a tumour caused by two mutational events. In the dominantly inherited form, one mutation is inherited via the germinal cells, and the second occurs in somatic cells. In the non-hereditary form, both mutations occur in somatic cells.

\section{Familial cases}

The familial group of cases exhibit autosomal dominant inheritance with incomplete penetrance (François and van Leuven, 1964). An affected individual has a 40-45 per cent chance of producing affected children (Warburg, 1974). Direct transmission is usual, but a generation may be skipped, while the disease occurs in collateral lines (Macklin, 1959).

In family groups, there is, in addition to phenotypically affected members, a percentage of carriers. It should be noted that some carriers show evidence of spontaneous tumour regression, while others (as in the reported family), do not.

\section{Summary}

Retinoblastoma occurring in four successive generations is described, followed by a brief discussion on the mode of inheritance of these tumours.

I am deeply indebted to Mr M. A. Bedford, Consultant Ophthalmologist at St Bartholomew's Hospital, for his encouragement and support, and for his permission to publish particulars of these cases.

\section{References}

François, J., and van Leuven, M. T. M. (1964) In 'Ocular and Adnexal Tumors', ed. M. Boniuk, p. 123. Mosby, St Louis

KNudson, A. G. (1971) Proc. nat. Acad. Sci. (Wash.), 68, 820

MACKLIN, M. T. (1959) Arch. Ophthal., 62, 842

MORGAN, S. S., and BAIR, H. L. (1968) Amer. F. Ophthal., 65, 43

SORSBY, A. (1972) Brit. med. $\mathcal{F}$., 2, 580

VOGEL, F. (1967) In 'Modern Trends in Ophthalmology', 4, ed. A. Sorsby, p. 34. Butterworths, London WARburg, M. (1974) In 'Genetic and Metabolic Eye Disease', ed. M. F. Goldberg, p. 447. Little, Brown, Boston 